\title{
Clarification of guava juice by an ultrafiltration process: analysis on the operating pressure, membrane fouling and juice qualities
}

\author{
${ }^{1}$ Omar, J.M., ${ }^{1, *}$ Nor, M.Z.M., ${ }^{1}$ Basri, M.S.M. and ${ }^{2}$ Che Pa, N.F. \\ ${ }^{1}$ Department of Process and Food Engineering, Faculty of Engineering, Universiti Putra Malaysia, 43400 \\ UPM Serdang, Selangor, Malaysia. \\ ${ }^{2}$ Department of Chemical Engineering Technology, Faculty of Engineering Technology, Universiti Tun \\ Hussein Onn Malaysia - Kampus (Cawangan Pagoh), 84600 Pagoh, Johor, Malaysia.
}

\begin{abstract}
Article history:
Received: 30 August 2019

Received in revised form: 17

October 2019

Accepted: 1 November 2019

Available Online: 10

February 2020
\end{abstract}

Keywords:

Fruit juice,

Guava,

Juice clarification,

Membrane process,

Ultrafiltration

DOI:

https://doi.org/10.26656/fr.2017.4(S1).S30

\begin{abstract}
Fresh guava juice was clarified using ultrafiltration (UF) process on a laboratory scale in this study. The observation was undertaken to determine the effect of the operating pressure (OP) on the permeate flux $(J)$ behaviour, the fouling mechanisms as well as the quality attributes of the guava juice i.e. $\mathrm{pH}$, turbidity, colour, total soluble solids (TSS), total phenolic content (TPC) and ascorbic acid content (AAC). The clarification of guava juice was performed in a batch mode using a $100 \mathrm{kDa}$ polymeric membrane in a dead-end module at an operating pressure OP of 1.0, 1.5, 2.0 and 2.5 bar. The results showed that a high OP resulted in high flux during the UF process. The flux-pressure curves exhibited no increase for an OP higher than 2.0 bar $\left(P_{\text {lim }}\right)$, with a limiting flux $\left(J_{\text {lim }}\right)$ identified at $17.22 \mathrm{~kg} / \mathrm{m}^{2} / \mathrm{hr}$. Intermediate and total pore-blocking has been identified as the major fouling mechanisms in the process. The resulting juice after filtration showed a reduction of more than $97 \%$ turbidity with a lower TSS by 7 to $17 \%$, compared to the fresh juice. The UF process permitted a good level of clarification with improvement in colour properties with a stable $\mathrm{pH}$ at 3.8 . However, a 19 to $27 \%$ and 18 to $22 \%$ reduction of TPC and AAC, respectively were found in the filtered juice with respect to the fresh juice. For appropriate flux behaviour and juice quality attributes, the process UF should be conducted at 2.0 bar.
\end{abstract}

\section{Introduction}

Guava (Psidium guajava L.) fruit is very popular in many tropical and subtropical countries. This fruit is usually consumed fresh as it contains a high level of vitamin $\mathrm{C}$ and lycopene compared to orange fruit (Akesowan and Choonhahirun, 2013). Further, it is rich in vitamin A, omega-3 and -6 polyunsaturated fatty acids, dietary fibre, potassium, magnesium, and antioxidant pigments such as carotenoid and polyphenols (Akesowan and Choonhahirun, 2013). Due to its high potential in a health-promoting capacity, researchers and producers have made various explorations with regards to utilising this fruit for the development of different food products. One of the options is to promote guava as a healthy fruit juice.

However, similar to other typical fruit juices, guava juice contains macromolecules (100 to $1000 \mathrm{ppm})$ mainly pectin and other polysaccharides such as cellulose, hemicellulose that may affect the quality of the juice if it is stored for longer periods than a few days for commercial use (Bhattacharjee et al., 2017). The colloids cause the juice to be cloudy as well as high in turbidity and viscosity which will reduce the consumer acceptance in some specific markets, either as pure guava juice or as mixtures with other juices (Ninga et al., 2018). Hence, efforts have been made to clarify guava juice through enzymatic treatment using pectinase (Akesowan and Choonhahirun, 2013; Ninga et al., 2018). However, this treatment may suffer a few drawbacks especially for industrial-scale applications such as the required processing conditions including temperature and $\mathrm{pH}$ that need to be closely monitored to ensure optimum enzyme reaction, and most of the enzymes are expensive to purchase or produce. In addition, improper disposal of the used enzymes may lead to environmental issues. Hence, a suitable processing method is needed to overcome these drawbacks by offering a feasible approach.

The membrane-based process offers an alternative to the conventional juice processing method e.g. enzymatic and heat treatment since it has many advantages such as 
the absence of phase transition or chemical agents, enjoys mild operating conditions, is low cost and is easy when scaling up (Castro-Muñoz et al., 2018). The membrane-based process is a method which selectively separates materials via pores and/or minute gaps in the molecular arrangement of a continuous structure (Bhattacharjee et al., 2017). It is classified by pore size and by the separation driving force, which includes microfiltration (MF), ultrafiltration (UF), reverse osmosis (RO) and nanofiltration (NF). Combination of membrane-based operations with other interesting applications have been suggested for replacement of conventional methodologies in fruit juice processing with most developed applications are related to the clarification and concentration of juices (Conidi et al., 2018). The application of membrane processes for fruit juices has been extensively studied for the juices of apple, orange, pineapple and kiwifruit with the focus on different processing parameters (operating pressure, feed $\mathrm{pH}$, feed concentration, crossflow velocity, temperature etc.) and juice quality attributes (clarity, color, $\mathrm{pH}$, nutritional content etc.) (Bhattacharjee et al., 2017). The advantages of using the membrane-based process are that it consumes lower energy which therefore reduces the operating cost, whilst allowing a significant improvement in the process efficiency and juice quality attributes such as colour, turbidity, and preservation of its natural bio-active compounds.

By considering its advantages, UF has great potential in guava juice processing. However, guava fruit has been minimally processed under industrial trials, and until now there have been no reports of processing guava juice by membrane technology. Thus, this study is aimed to explore the potential of applying the membrane-based process using ultrafiltration (UF) for guava juice clarification by observing its effect on the permeate flux behaviour, fouling mechanism and guava juice quality attributes. The information in this study will provide valuable insights for juice processing especially for the utilization of local guava fruit.

\section{Materials and methods}

\subsection{Guava juice preparation}

White guavas (Psidium guajava L.) of the GU8 variety which were fully-ripe and free from visual blemishes and bruises were purchased from a local market in Seri Kembangan, Malaysia. The fruits were washed with tap water, the skin peeled off and the fruit cut into small pieces. The peeled guavas were then processed using a juice extractor (PJ6900S, Pensonic, Malaysia). The guava fruit extract was filtered through a cheesecloth prior to centrifugation at $9000 \mathrm{rpm}$ for
15 mins. The supernatant obtained was used as a feed for the ultrafiltration (UF) process.

\subsection{UF experimental set-up and procedures}

This process was carried out using a laboratory-scale membrane stirred cell unit (Amicon $\AA$, Millipore, USA) with a compressed air tank attached. The system was equipped with a polyethersulphone dead-end disc membrane with a molecular weight cut-off (MWCO) of $100 \mathrm{kDa}$, which has been reported to be suitable for clarification of natural juices and agro-food by-products (Castro-Muñoz et al., 2018). The specification of the membrane used for the guava juice clarification in this study is shown in Table 1. Each UF experiment performed was executed with a capacity of $250 \mathrm{~mL}$ of juice at different operating pressures (OP) of 1, 1.5, 2 and $2.5 \mathrm{bar}$ in order to find the limiting $\mathrm{OP}\left(\mathrm{OP}_{\text {lim }}\right)$ that provided the maximum permeate flux for carrying out the batch concentration mode (Cassano et al., 2007). The filtration process for each run was performed until it reached $80 \%$ of permeate recovery (PR) for the convenience of the process as described in Equation (1):

$$
\operatorname{PR}(\%)=\frac{v_{p}}{v_{\mathrm{f}}} \times 100
$$

Where $V_{f}$ and $V_{p}$ are the volume (g) of the feed and permeate, respectively. The performance of the UF process was measured in terms of the permeate flux $(J)$ as described in Equation (2):

$$
I=\frac{1}{\mathrm{~A}_{\mathrm{m}}} \times \frac{\Delta \mathrm{W}}{\Delta t}
$$

Where $A_{m}$ is the effective membrane area $\left(\mathrm{m}^{2}\right)$ and $(\Delta \mathrm{W} /$ $\Delta t)$ is the permeate weight $\Delta \mathrm{W}$ collected over time $\Delta t$ $\left(\mathrm{kg} \cdot \mathrm{h}^{-1}\right)$

Table 1. The specifications of the membrane used for the guava juice clarification

\begin{tabular}{ll}
\hline Manufacturer & EMD Millipore Corporation \\
\hline Configuration & Dead-end \\
MWCO $(\mathrm{Da})$ & 100,000 \\
Membrane material & Polyethersulphon (PES) \\
Membrane area $\left(\mathrm{m}^{2}\right)$ & 0.0032 \\
Filter diameter $(\mathrm{mm})$ & 63.5 \\
\hline
\end{tabular}

\subsection{Modelling of the membrane fouling mechanism}

In order to understand the fouling mechanism during the process, the flux decline was analysed through four types of fouling models, corresponding to cake formation, intermediate pore blocking, internal pore blocking and complete pore blocking phenomenon (Hermia, 1982). An explanation of each model is given below (Nor et al., 2017):

Cake formation $(\mathrm{n}=0)$ occurs when particles form a gel layer over the membrane surface and can be 
described by Equation (3):

$$
J=J^{*}+\left(J_{\circ}-J^{*}\right) e^{\left(-k_{a} t\right)}
$$

Intermediate pore blocking $(\mathrm{n}=1)$ takes place when particles settle on other particles that have already been deposited on the membrane surface, which already block some pores and/or directly block an area of the membrane. It can be described by Equation (4):

$$
I=\frac{J_{0} J^{*} e^{-k_{b} J^{*} t}}{J^{*}+J_{0}\left(e^{-k_{b} t}-1\right)}
$$

Internal pore blocking $(n=1.5)$ takes place when the particles enter the membrane pores and are deposited over the pore walls, reducing the membrane pore volume, as described by Equation (5):

$$
\frac{1}{J^{1 / 2}}=\frac{1}{J_{0}^{1 / 2}}+k_{c} t
$$

Complete pore blocking $(n=2)$ arises when particles block the membrane surface by means of pore sealing and can be described by Equation (6):

$$
t=\frac{1}{K_{d} J^{*^{2}}} \ln \left[\left(\frac{J}{J_{0}} \frac{J_{0}-J^{*}}{J-J^{*}}\right)-J^{*}\left(\frac{1}{J}-\frac{1}{J_{0}}\right)\right]
$$

Where $J_{o}$ is the initial permeate flux, $J^{*}$ is the steadystate permeate flux and the $k_{a}, k_{b}, k_{c}$, and $k_{d}$ in these models are constants.

The experimental data in this study was fitted to each model using the Solver function in Microsoft Excel 2013 (USA) to identify the fouling mechanism involved during the ultrafiltration process. Four optimisation runs were performed for each experimental flux profile by assigning $n=0,1,1.5$ and 2 where the residual sum of squares (RSS) between numerical predictions and experimental data for each run were compared for the lowest RSS to determine the main fouling mechanism.

\section{$2.4 \mathrm{pH}$, total soluble solids and turbidity measurement}

The $\mathrm{pH}$ of the samples was determined using a $\mathrm{pH}$ meter model (Con 700, Oakton, USA). It was calibrated with a buffer solution of $\mathrm{pH} 4$ and 7 . The total soluble solids (TSS) were measured in terms of ${ }^{\circ}$ Brix using a hand refractometer (PAL-3, Atago Co., Japan). Turbidity in the samples was determined using a microprocessor turbidity-meter (TN-100, Eutech Instrument, Singapore) and was calibrated with patron solution 0-1000 NTU.

\subsection{Color measurement}

The color properties were determined using a colorimeter (CS-2000, Konica Minolta, USA Data were expressed in terms of $\mathrm{L}^{*}$ (lightness index), a* (rednessgreenness) and $b^{*}$ (yellowness-blueness). Chroma is used to determine the degree of difference of a hue in comparison with gray color with the same lightness and is considered the quantitative attribute of colorfulness.
The chroma (c) and hue (h) were calculated using the following Equation 7 and 8:

$$
\begin{aligned}
& c=\left(a^{* 2}+b^{* 2}\right)^{1 / 2} \\
& \mathrm{~h}=\tan ^{-1}\left(\frac{\mathrm{b}^{*}}{\mathrm{a}^{*}}\right)
\end{aligned}
$$

\subsection{Total phenolic content determination}

The total phenolic content was determined colourimetrically with a Folin-Ciocalteau assay, which depended on the reduction of a Folin-Ciocalteau reagent by phenolic compounds under alkaline conditions. Some $0.3 \mathrm{~mL}$ of guava juice sample was added into $1.5 \mathrm{~mL}$ of $10 \%$ Folin reagent $(10 \mathrm{~mL}$ Folin reagent diluted with $90 \mathrm{~mL}$ of distilled water) and $1.2 \mathrm{~mL}$ of $7.5 \%$ sodium carbonate, $\mathrm{Na}_{2} \mathrm{CO}_{3}\left(7.5 \mathrm{~g}\right.$ of $\mathrm{Na}_{2} \mathrm{CO}_{3}$ in $100 \mathrm{~mL}$ of solution). The absorbance of the solution was measured at $765 \mathrm{~nm}$ with a Shimadzu UV-VIS spectrophotometer (Ultraspec 3100 Pro, Amersham Pharmacia Biotech, UK). The standard curve was established using gallic acid. The total phenolic content was expressed as a gallic acid equivalent in $\mathrm{mg} / \mathrm{L}$.

\subsection{Ascorbic acid content determination}

The sample was diluted with distilled water (1:1) prior to titration against dichlorophenolindophenol (DCPIP) solution. The endpoint of the titration was identified when a pink colour appeared, which lasted for at least $30 \mathrm{~s}$. The mass of ascorbic acid (mg) in the sample was calculated based on the volume of titrated DCPIP solution.

\subsection{Statistical analysis}

The filtration of guava juice was carried out in duplicate, and all analyses were carried out in triplicate. The data was subject to examination for one-way analysis of variance (ANOVA) using Statistical Analysis System (SAS) software (Version 9.2, SAS Institute, USA). Significant differences between means were compared by a t-test at the $5 \%$ level of significance.

\section{Results and discussion}

\subsection{Evaluation of flux behaviour}

Figure 1(a) shows the behaviour of the permeate flux $\left(J_{p}\right)$ as a function of time $(t)$ at different operating pressures of 1, 1.5, 2, and 2.5 bar. Based on the graph, 1 bar OP exhibited the lowest initial flux $\left(14.0 \mathrm{~kg} / \mathrm{m}^{2} / \mathrm{hr}\right)$ and took the longest time to achieve $80 \%$ of the permeate recovery (PR), which was about 800 mins. In contrast, 2.5 bar OP resulted in the highest initial flux of $55.3 \mathrm{~kg} /$ $\mathrm{m}^{2} / \mathrm{hr}$ and completed the process in 220 mins. This finding was expected since the increase in permeate flux with pressure was due to the higher driving force across 
the membrane (Nor et al., 2017), which was similar to other findings concerning juice filtration of kiwi fruit (Cassano et al., 2007) and xoconostle (Castro-Muñoz et al., 2018).

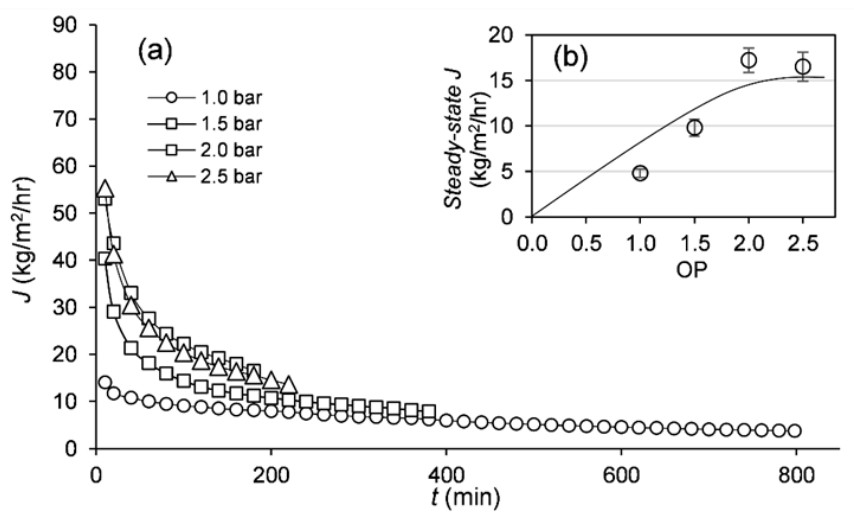

Figure 1. Permeate flux $(J)$ profiles (a) $J$ on the function of time $(t)$ at different operating pressures (OP); (b) Steady-state $J$ on the function of OP

Decreasing trends of the flux towards the end of the process up to the steady-state values were observed at all operating pressures as shown in Figure 1(a). There were three stages of flux decline in all the flux profiles. The first stage could be identified as a drastic reduction state that occurred during approximately the first 30 mins of the process. The second stage (minor flux reduction) was observed subsequently before the third stage (steadystate), where a non-variation of permeate flux as a function of time occurred until reaching the final permeate flux. The trends were strongly related to the fouling phenomenon taking place on the surface membrane during the filtration process. The gel polarisation phenomenon occurred when the feed passed through the membrane and left suspended solids behind. Subsequently, the rejected particles (suspended solids) started to deposit on the membrane surfaces to create fouling. Hence, the rate of flux decreased (Castro-Muñoz et al., 2018).

In general, the steady-state $J_{p}$ increased with the increase of pressure from 1 to 2 bar, as shown in Figure 1(b). However, the steady-state $J_{p}$ became independent of pressure after 2 bar of OP. The typical permeate flux showed a deviation from a linear fluxpressure behaviour as the pressure increased, and it became independent of pressure after reaching its limiting pressure, $P_{\text {lim }}$ (Castro-Muñoz et al., 2018). The $P_{\text {lim }}$ occurred when the permeate flux was not governed by the driving force, but it was governed by the fouling and polarisation-concentration phenomena (Cassano et al., 2007). At this point onwards, the fouling layer had consolidated itself, hence the prevailing forces could no longer facilitate in increasing the filtration rate, resulting in no significant change in the flux values. The limiting pressure gave the maximum permeate flux (known as the limiting flux, $J_{\text {lim }}$ ) produced by the driving force. In this study, the $J_{\text {lim }}$ of $17.22 \mathrm{~kg} / \mathrm{m}^{2} / \mathrm{hr}$ was observed at an OP of 2.0 bar where there was no significant rise of the permeate flux at a higher pressure. Hence, 2.0 bar pressure can be considered as the limiting pressure $\left(P_{\text {lim }}\right)$ in this study.

\subsection{Identification of mechanism responsible for flux decline}

As fruit juices contain a noteworthy measure of macromolecules e.g., polysaccharides (pectins, cellulose, hemicellulose, and starch), dimness shaping segments (suspended solids (SS), colloidal particles, proteins, and polyphenols (Bhattacharjee et al., 2017), which will cause the formation of fouling, the control of the process parameters including pressure is necessary to minimise the impact on the flux performance. Table 2 shows the residual sum of squares (RSS) for the non-linear regression associated with various pore blocking models, i.e., cake formation $(\mathrm{n}=0)$, intermediate pore blocking $(n=1)$, internal pore blocking $(n=1.5)$ and complete pore blocking $(n=2)$. The lowest RSS of each operating pressure (OP) indicates the best model to represent the experimental data, although there is a possibility that more than one mechanism may be involved (Nor et al., 2017). Based on Table 2, the most prominent fouling mechanism in the process is the intermediate pore blocking $(n=1)$, except for the process at the higher OP of 2.5, which showed close RSS values between the $n=1$ and $n=2$ models (complete pore blocking).

The fouling mechanism that occurred on the membrane surface in this study evolved from an intermediate to a complete pore blocking condition depending on the operating pressure. This might be

Table 2. Residual sum of squares (RSS) for the non-linear regression of different fouling models in the UF process

\begin{tabular}{ccccccccc}
\hline \multirow{2}{*}{$\begin{array}{c}\text { Operating } \\
\text { pressure (bar) }\end{array}$} & \multicolumn{9}{c}{ Pore blocking models } \\
\cline { 2 - 10 } & \multicolumn{2}{c}{ Cake formation (n=0) } & \multicolumn{2}{c}{$\begin{array}{c}\text { Intermediate pore } \\
\text { blocking }(\mathrm{n}=1)\end{array}$} & $\begin{array}{c}\text { Internal pore blocking } \\
(\mathrm{n}=1.5)\end{array}$ & $\begin{array}{c}\text { Complete pore blocking } \\
(\mathrm{n}=2)\end{array}$ \\
\cline { 2 - 11 } & $K_{a}$ & $\mathrm{RSS}$ & $K_{b}$ & $\mathrm{RSS}$ & $K_{c}$ & $\mathrm{RSS}$ & $K_{d}$ & $\mathrm{RSS}$ \\
\hline 1 & 0.0046 & 32.1471 & 0.0005 & $18.9331^{*}$ & 0.0004 & 54.0851 & 0.0002 & 2674192 \\
1.5 & 0.0568 & 843.071 & 0.0011 & $311.199 *$ & 0.0022 & 2336.77 & 0.0001 & 89487.2 \\
2 & 0.0442 & 512.653 & 0.0008 & $168.4934^{*}$ & 0.0015 & 1490.1 & $5.43 \times 10^{-5}$ & 11312.6 \\
2.5 & 0.0577 & 959.807 & 0.0009 & 417.1894 & 0.002 & 2153.63 & $5.43 \times 10^{-5}$ & $406.919^{*}$ \\
\hline
\end{tabular}

* The smallest RSS for each experimental data block 
because, at a higher OP, more absorption of nonpermeating molecules occurred on the membrane surface which subsequently led to the pores becoming blocked completely. Studies of the filtration of other fruit juices identified different fouling mechanisms, which were due to the natural compositions of the sample. For example, intermediate pore blocking followed with cake filtration represents the most competent combination of fouling mechanisms for the observed membrane flux decline in the clarification of pequi fruit juice (de Santana Magalhães et al., 2018). However, for the clarification of kiwi juice the cake filtration fouling mechanism was predominant (Cassano et al., 2008).

\subsection{Evaluation of quality attributes of the clarified guava juice}

\subsection{1 $\mathrm{pH}$ and total soluble solids}

Table 3 shows the $\mathrm{pH}$ and total soluble solids (TSS) of the samples at different operating pressures (OP) of the process. Based on Table 3, there are no significant differences in $\mathrm{pH}$ values $(\mathrm{p}<0.05)$ in the fresh (feed), clarified (permeate) and retained juice (retentate) at $\mathrm{OP}$ values of 1.0, 1.5, 2.0, and 2.5 bar. This result indicates that the ultrafiltration process does not affect the $\mathrm{pH}$ value of clarified guava juice. This finding is in agreement with previous studies of different fruit juices (Cassano et al., 2008; Castro-Muñoz et al., 2018).

Furthermore, the UF process has resulted in some reduction of TSS in the permeate of the guava juice as shown in Table 3. At 1 bar, there was a slight decrease in total soluble solids from 5.3 to $4.92 \quad(7.1 \%$ TSS reduction) in the permeate when compared to the fresh guava juice (feed). The same condition was observed in other OPs where the TSS decreased by 14.4, 17.4 and $7.1 \%$ for an OP of 1.5, 2.0 and 2.5 bar, respectively. Although no obvious relationship between OPs and TSS reduction in the permeate, this result indicates that the UF process has managed to remove some of the suspended solids from the guava juice. It can be supported by the higher TSS values in the retentate of all samples compared to the feed, reflecting the retention of the soluble solids by the membrane. The inconsistency of TSS values in feed, permeate and retentate at different OP in this study occurred might be due to the variation of its initial value in the feed. The TSS generally consisted of low molecular weight compounds such as sugars (sucrose, glucose, and fructose), mineral salts and some organic acids (Castro-Muñoz et al., 2018). The literature has reported similar findings in the juice clarification of Xoconostle (prickly pear) (Castro-Muñoz et al., 2018) and kiwi fruit (Cassano et al., 2007).

As the TSS were concentrated in the retentate stream, this leads to a decline in the flux during the process due to the fouling layers formed by a combination of suspended solids and adsorbed macromolecular impurities (Cassano et al., 2007).

\subsubsection{Turbidity and colour}

Figure 2 shows the turbidity of the samples at the different OP of 1 to 2.5 bar. The turbidity of the clarified guava juice for all samples was drastically reduced when compared to the feed. The turbidity of the permeate after the UF process was almost completely removed, with all the filtered samples exhibiting a greater than 97\% reduction of turbidity, resulting in higher clarity of the guava juice. Similar results have been reported for the clarification of banana, pineapple, blackberry, melon and apple juice through membrane filtration where the turbidity was greatly reduced in the permeate and was high in the retentate stream (Bhattacharjee et al., 2017).

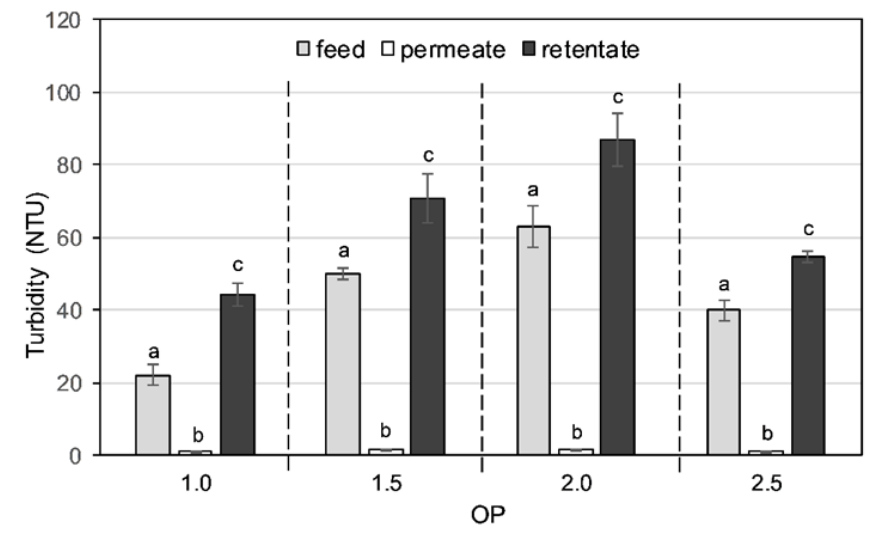

Figure 2. Turbidity of UF samples at different operating pressure (OP) (Different letters in the same section indicate the significant differences of $\mathrm{p}<0.05)$

The removal of turbidity can be associated with TSS reduction in the clarified juice. Generally, the turbidity considers the presence of fibres, suspended solids, high molecular weight carbohydrates and TSS (Castro-Muñoz et al., 2018). Most of these non-permeating molecules were accumulated on the membrane surface during the process, causing high turbidity and TSS of the retentates

Table 3. Analysis of $\mathrm{pH}$ and TSS of the guava juice submitted to UF at different operating pressures

\begin{tabular}{ccccccc}
\hline \multirow{2}{*}{ Operating pressure (bar) } & \multicolumn{3}{c}{$\mathrm{pH}$} & \multicolumn{3}{c}{ TSS ( ${ }^{\circ}$ Brix) } \\
\cline { 2 - 7 } & Feed & Permeate & Retentate & Feed & Permeate & Retentate \\
\hline 1 & $3.78 \pm 0.01^{\mathrm{a}}$ & $3.81 \pm 0.01^{\mathrm{a}}$ & $3.79 \pm 0.00^{\mathrm{a}}$ & $5.30 \pm 0.28^{\mathrm{a}}$ & $4.92 \pm 0.07^{\mathrm{a}}$ & $5.48 \pm 0.306^{\mathrm{a}}$ \\
1.5 & $3.86 \pm 0.01^{\mathrm{a}}$ & $3.88 \pm 0.00^{\mathrm{a}}$ & $3.87 \pm 0.01^{\mathrm{a}}$ & $7.15 \pm 0.85^{\mathrm{a}}$ & $6.12 \pm 0.56^{\mathrm{b}}$ & $7.60 \pm 0.94^{\mathrm{a}}$ \\
2 & $3.73 \pm 0.01^{\mathrm{a}}$ & $3.73 \pm 0.01^{\mathrm{a}}$ & $3.72 \pm 0.00^{\mathrm{a}}$ & $6.30 \pm 0.19^{\mathrm{a}}$ & $5.20 \pm 0.12^{\mathrm{b}}$ & $7.65 \pm 0.78^{\mathrm{a}}$ \\
2.5 & $3.85 \pm 0.02^{\mathrm{a}}$ & $3.87 \pm 0.00^{\mathrm{a}}$ & $3.87 \pm 0.00^{\mathrm{a}}$ & $7.25 \pm 0.33^{\mathrm{a}}$ & $6.73 \pm 0.15^{\mathrm{b}}$ & $7.97 \pm 0.28^{\mathrm{a}}$ \\
\hline
\end{tabular}

$*$ Means $( \pm$ SD) with the different letters are significantly different at $\mathrm{p}<0.05$ for each row of the section 
and subsequently linked to the flux decay as discussed in the previous section.

The positive changes in terms of the physical aspects of the guava juice, including its turbidity, is important due to the high demand of consumers for the good appearance of the fruit juice. Clear fruit juice is more attractive to humans for consumption (Castro-Muñoz et al., 2018). This attribute can be reflected in the colour properties of the juice. Figure 3 exhibits the colour changes of the guava juice before and after the UF process. The filtered guava juice looks "light" and "sparkling clear" compared to the feed and retentate. This can be further supported by the colour properties of the samples, represented by lightness/darkness $\left(\mathrm{L}^{*}\right)$, greenness/redness $\left(a^{*}\right)$ and yellowness/blueness $\left(b^{*}\right)$, as shown in Table 4.

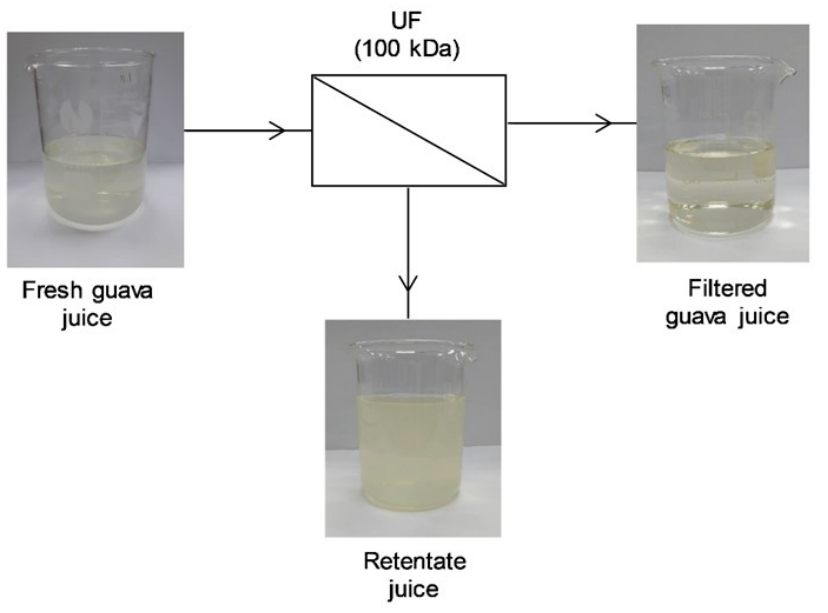

Figure 3. Guava juice samples by the ultrafiltration process

Based on Table 4, the permeate for all OP processes exhibited an increase in $\mathrm{L}^{*}$ value compared to the feed. Meanwhile, the UF also managed to reduce the $\mathrm{a}^{*}$ and $b^{*}$ values in all permeate, indicating that the clarified juice is lighter in colour with some degree of greenness and blueness. Further, the $\mathrm{h}^{\circ}$ value for all the permeates also increased while the brightness (chroma) decreased after the filtration process, which indicated that the clarified juice behaved by moving in the direction of "clear" juice.

\subsubsection{Total phenolic content (TPC) and ascorbic acid content (AAC)}

Table 5 shows the total phenolic content (TPC) and ascorbic acid of the samples after the UF process at the different operating pressures (OP) of 1 to 2.5 bar. Overall, a reduction of TPC has been identified after the guava juice was filtered, with 19.7, 27.64, 20.4 and $24.52 \%$ reduction when the process was performed at an OP of 1.0, 1.5, 2.0 and 2.5 bar, respectively. Reductions in turbidity and total solids are desirable to obtain a clarified extract, but reductions in polyphenols compromise the nutrition quality of the extract (de Santana Magalhães et al., 2019). The reduction of TPC in the permeate might be due to interaction with compounds rejected by the membranes (Castro-Muñoz et al., 2018). For example, the loss of the phenolic compounds can be linked with the continuous action of polyphenol oxidases in the retentate (Cassano et al., 2008). Variation in the initial TPC values in the feed has caused some inconsistencies of its values in the samples at different OP in this study. Nevertheless, based on the finding in this study, the TPC reduction may not be dependent on the variation of the OP. Although TPC reflects the antioxidant properties of the juice, it is also related to the astringency of the product. Hence, the TPC rejection in this study signifies that the astringency of the clarified juice has also been reduced, which might be a good alternative from the sensory perspective.

Table 4. Analysis of colour properties of guava juice submitted to UF at different operating pressures

\begin{tabular}{|c|c|c|c|c|c|c|}
\hline \multirow{2}{*}{ Operating pressure (bar) } & \multirow{2}{*}{ Samples } & \multicolumn{5}{|c|}{ Colour } \\
\hline & & $\mathrm{L}^{*}$ & $a^{*}$ & $b^{*}$ & Hue angle $\left({ }^{\circ}\right)$ & Chroma \\
\hline \multirow{3}{*}{1} & Feed & $31.05 \pm 0.29^{c}$ & $-0.05 \pm 0.00^{\mathrm{a}}$ & $0.68 \pm 0.06^{\mathrm{b}}$ & $-85.70^{c}$ & $0.23^{\mathrm{b}}$ \\
\hline & Permeate & $32.21 \pm 0.78^{\mathrm{a}}$ & $-0.25 \pm 0.01^{b}$ & $0.22 \pm 0.07^{\mathrm{c}}$ & $0.03^{\mathrm{a}}$ & $0.06^{\mathrm{c}}$ \\
\hline & Retentate & $31.85 \pm 0.17^{\mathrm{bc}}$ & $-0.14 \pm 0.17^{\mathrm{a}}$ & $0.73 \pm 0.05^{\mathrm{a}}$ & $-79.34^{b}$ & $0.28^{\mathrm{a}}$ \\
\hline \multirow{3}{*}{1.5} & Feed & $32.25 \pm 0.17^{\mathrm{b}}$ & $-0.10 \pm 0.01^{\mathrm{a}}$ & $0.56 \pm 0.02^{\mathrm{b}}$ & $-90.05^{\mathrm{b}}$ & $0.23^{b}$ \\
\hline & Permeate & $33.91 \pm 0.32^{\mathrm{a}}$ & $-0.28 \pm 0.03^{\mathrm{c}}$ & $0.32 \pm 0.04^{\mathrm{c}}$ & $0.16^{\mathrm{a}}$ & $0.06^{\mathrm{c}}$ \\
\hline & Retentate & $32.05 \pm 0.02^{\mathrm{b}}$ & $-0.12 \pm 0.08^{\mathrm{b}}$ & $0.62 \pm 0.05^{\mathrm{a}}$ & $-89.45^{\mathrm{b}}$ & $0.28^{\mathrm{a}}$ \\
\hline \multirow{3}{*}{2} & Feed & $32.27 \pm 0.038^{\mathrm{ab}}$ & $-0.14 \pm 0.16^{\mathrm{a}}$ & $1.25 \pm 0.19^{\mathrm{a}}$ & $-84.12^{c}$ & $0.80^{\mathrm{b}}$ \\
\hline & Permeate & $32.93 \pm 0.75^{\mathrm{a}}$ & $-0.38 \pm 0.05^{\mathrm{b}}$ & $0.26 \pm 0.21^{\mathrm{b}}$ & $-22.43^{\mathrm{a}}$ & $0.26^{\mathrm{c}}$ \\
\hline & Retentate & $31.80 \pm 0.08^{\mathrm{c}}$ & $-0.18 \pm 0.09^{\mathrm{a}}$ & $1.12 \pm 0.10^{\mathrm{a}}$ & $-80.90^{\mathrm{b}}$ & $0.64^{\mathrm{b}}$ \\
\hline \multirow{3}{*}{2.5} & Feed & $31.73 \pm 0.04^{\mathrm{b}}$ & $-0.01 \pm 0.05^{\mathrm{a}}$ & $0.85 \pm 0.13^{\mathrm{ab}}$ & $-42.15^{b}$ & $0.38^{\mathrm{b}}$ \\
\hline & Permeate & $32.27 \pm 1.20^{\mathrm{a}}$ & $-0.25 \pm 0.09^{\mathrm{c}}$ & $0.50 \pm 0.04^{\mathrm{c}}$ & $0.44^{\mathrm{a}}$ & $0.16^{\mathrm{c}}$ \\
\hline & Retentate & $31.50 \pm 0.51^{\mathrm{b}}$ & $-0.16 \pm 0.08^{b}$ & $1.05 \pm 0.10^{\mathrm{a}}$ & $-74.94^{\mathrm{c}}$ & $0.59^{\mathrm{a}}$ \\
\hline
\end{tabular}

$*$ Means $( \pm \mathrm{SD})$ with the different letters are significantly different at $\mathrm{p}<0.05$ for each row of the section 
Table 5. Analysis of total phenolic content (TPC) and ascorbic acid content (AAC) of guava juice submitted to UF at different operating pressures

\begin{tabular}{ccccccc}
\hline \multirow{2}{*}{ Operating pressure (bar) } & \multicolumn{3}{c}{ TPC $(\mathrm{mg} / \mathrm{L})$} & & AAC \\
\cline { 2 - 7 } & Feed & Permeate & Retentate & Feed & Permeate & Retentate \\
\hline 1 & $100.43 \pm 3.78^{\mathrm{a}}$ & $80.61 \pm 0.82^{\mathrm{c}}$ & $92.61 \pm 1.25^{\mathrm{b}}$ & $28.92 \pm 0.10^{\mathrm{a}}$ & $22.49 \pm 1.52^{\mathrm{c}}$ & $31.595 \pm 01.36^{\mathrm{ab}}$ \\
1.5 & $204.04 \pm 1.02^{\mathrm{a}}$ & $147.64 \pm 1.54^{\mathrm{c}}$ & $178.09 \pm 4.51^{\mathrm{b}}$ & $30.52 \pm 0.76^{\mathrm{a}}$ & $24.36 \pm 1.62^{\mathrm{c}}$ & $27.846 \pm 0.12^{\mathrm{ab}}$ \\
2 & $212.14 \pm 5.68^{\mathrm{a}}$ & $168.90 \pm 0.99^{\mathrm{c}}$ & $197.01 \pm 1.33^{\mathrm{b}}$ & $28.92 \pm 1.52^{\mathrm{a}}$ & $23.56 \pm 1.52^{\mathrm{b}}$ & $27.846 \pm 0.76^{\mathrm{a}}$ \\
2.5 & $131.96 \pm 1.85^{\mathrm{a}}$ & $99.61 \pm 1.68^{\mathrm{c}}$ & $122.95 \pm 2.66^{\mathrm{b}}$ & $29.54 \pm 0.49^{\mathrm{a}}$ & $24.10 \pm 0.76^{\mathrm{b}}$ & $29.48 \pm 0.80^{\mathrm{a}}$ \\
\hline
\end{tabular}

*Means $( \pm$ SD) with the different letters are significantly different at $\mathrm{p}<0.05$ for each row of the section

The ascorbic acid content (AAC) in white seeded guava fruit is known to be superior when compared to other fruits such as orange, banana, dragon fruit and star fruit. Hence, this study investigated the effect of the UF process on the AAC in the guava juice. Based on Table 5, the AAC in the permeate was found to be lower compared to the feed at all OP. The ACC reduced by $22.2,20.2,18.5$ and $18.4 \%$ at an OP of 1.0, 1.5, 2.0 and 2.5 bar, respectively. Similar AAC reduction of $16.7 \%$ was observed in filtered kiwi fruit juice during the membrane filtration process as a result of oxidation during the filtration process (Cassano et al., 2007). Similar to TPC, the AAC is believed to be unaffected affected by variations in the operating pressure.

\section{Conclusion}

Clarification of guava juice was achieved by a UF process, and insight was provided in terms of the flux profile at different operating pressures (OP), the fouling mechanism involved and the quality attributes of the juice. The permeate flux of the UF stages was found to be dependent on the OP, up to 2.0 bar, where no significant flux increase occurred at the higher pressure. Hence, 2.0 bar was determined as the limiting pressure of the process. For an OP less than 2.0 bar, intermediate pore blocking has been identified as the major fouling mechanism of the process, while total pore-blocking fouling predominated the UF at an OP of 2.5 bar. The UF process in this study permitted a good level of clarification by reducing the total soluble solids (TSS) and turbidity in the guava juice while maintaining the $\mathrm{pH}$ and enhancing the colour properties. However, due to oxidation and solute interactions, some reduction of the total phenolic content (TPC), and ascorbic acid content (AAC) were observed in the permeates with respect to the fresh juice. Nevertheless, from the sensory perspective, the reduction of TPC might be a good alternative since the astringency of the clarified juice was also expected to be reduced. Based on the permeation flux profiles and quality attributes of the guava juice, the best operating pressure of the UF process condition should be at 2.0 bar. Exploration of the clarification of guava juice through UF process can be further extended in the future by incorporating the enzymatic pre- treatment for higher processing efficiency.

\section{Acknowledgment}

The authors would like to thank the Ministry of Education Malaysia for sponsoring this work under UPM Putra Grant: GP/2018/9656000.

\section{References}

Akesowan, A., and Choonhahirun, A. (2013). Effect of enzyme treatment on guava juice production using response surface methodology. Journal of Animal and Plant Sciences, 23(1), 114-120.

Bhattacharjee, C., Saxena, V.K., and Dutta, S. (2017). Fruit juice processing using membrane technology: A review. Innovative Food Science and Emerging Technologies, 43, 136-153. https://doi.org/10.1016/ j.ifset.2017.08.002

Cassano, A., Donato, L., Conidi, C. and Drioli, E. (2008). Recovery of bioactive compounds in kiwifruit juice by ultrafiltration. Innovative Food Science and Emerging Technologies, 9(4), 556-562. https://doi.org/10.1016/j.ifset.2008.03.004

Cassano, A, Donato, L., and Drioli, E. (2007). Ultrafiltration of kiwifruit juice: Operating parameters, juice quality and membrane fouling. Journal of Food Engineering, 79(2), 613-621. https://doi.org/10.1016/j.jfoodeng.2006.02.020

Castro-Muñoz, R., Fíla, V., Barragán-Huerta, B.E., Yáñez-Fernández, J., Piña-Rosas, J.A. and ArboledaMejía, J. (2018). Processing of Xoconostle fruit (Opuntia joconostle) juice for improving its commercialization using membrane filtration. Journal of Food Processing and Preservation, 42(1), 1-9. https://doi.org/10.1111/jfpp.13394

Conidi, C., Drioli, E. and Cassano, A. (2018). Membrane -based agro-food production processes for polyphenol separation, purification and concentration. Current Opinion in Food Science, 23, 149-164. https://doi.org/10.1016/j.cofs.2017.10.009

de Santana Magalhães, F., Cardoso, V.L. and Reis, M.H.M. (2018). Sequential process with bioadsorbents and microfiltration for clarification of 
pequi (Caryocar brasiliense Camb.) fruit extract. Food and Bioproducts Processing, 108, 105-116. https://doi.org/10.1016/j.fbp.2018.02.003

de Santana Magalhães, F., Sá, M.D.S.M., Cardoso, V.L. and Reis, M.H.M. (2019). Recovery of phenolic compounds from pequi (Caryocar brasiliense Camb.) fruit extract by membrane filtrations: Comparison of direct and sequential processes. Journal of Food Engineering, 257, 26-33. https:// doi.org/10.1016/j.jfoodeng.2019.03.025

Hermia, J. (1982). Constant Pressure Blocking Filtration Laws-Application to Power-Law Non-Newtonian Fluids. Transaction of the Institution of Chemical Engineers, 60, 183-187.

Ninga, K.A., Sengupta, S., Jain, A., Desobgo, Z.S.C., Nso, E.J., and De, S. (2018). Kinetics of enzymatic hydrolysis of pectinaceous matter in guava juice. Journal of Food Engineering, 221, 158-166. https:// doi.org/10.1016/j.jfoodeng.2017.10.022

Nor, M.Z.M., Ramchandran, L., Duke, M., and Vasiljevic, T. (2017). Integrated ultrafiltration process for the recovery of bromelain from pineapple waste mixture. Journal of Food Process Engineering, 40(3), 1-9. https://doi.org/10.1111/ jfpe. 12492 